\title{
Kinematics and Comparative Anatomy of Some Limb Bones of the African Elephant (Loxodonta africana) and Large Domestic Animals
}

\author{
Melaku Tefera \\ College of Veterinary Medicine, Haramaya University. \\ P.O. Box 144 Haramaya Campus. Ethiopia. 251-0914722459, melaku22@yahoo.com
}

Received May, accepted for publication December, 2011

\section{Abstract}

Elephants are the largest extant terrestrial animals and the archetype of 'graviportal' animals, with large body size and a pattern of pentadactyl limbs. The fundamental structures are homologous in all tetrapods but in the course of evolution these structures have been modified in the elephant. Osteometric parameters show that the relationship of the length of the femur to the circumference is $2.5,2.75$ and 2.8 in elephant, horse and cattle respectively. Similarly humerus length to circumference is 2.3 in the three species showing isometric scaling. There is a positive allometric scaling between bone weight and bone length; the ratio of femur length to weight is $205 \mathrm{~g} / \mathrm{cm}, 72 \mathrm{~g} / \mathrm{cm}$ and $64 \mathrm{~g} / \mathrm{cm}$ in elephants, horses and cattle. The ratio of weight of the humerus to length or weights of the humerus plus femur to their combined length is a good estimate of the body weight in $\mathrm{kg}=\left(\frac{w h}{l h} \times 10\right)$. We have observed three gaits in the elephant: slow, fast walk, and trot. Either one or a maximum of two controlateral legs are lifted from ground, but never two ipislateral limbs. The propulsive force originates from the retractor muscles of the hind legs, elephants moving by extension of the forelegs rather than flexion. The head's conical structure makes it aerodynamically efficient, serving as nose cone. The joint Articulatio atlanto occipitalis is less movable than the horse or cattle. The main mechanism by which an elephant overcomes the effect of heavy weight is by having high density bones. The articular surfaces of the bones are less developed in elephant compared to horse or cattle, resulting in poor angular movements with less ground shock waves. The pes is like a cushion filled with a fat layer that serves as a shock absorber. The skull is spongy and the arrangement 
of trabeculae makes the skull lighter in weight.

\section{Key words}

biomechanics, bone allometry, comparative anatomy, elephant, gait, osteology, skeleton, aerodynamics.

\section{Introduction}

The Order Proboscidea includes the animals with elongated trunks that function both as nose and as a prehensile organ to grasp and manipulate objects in the environment. Modern elephants are the heaviest land animals, no other terrestrial animal weighs half as much (McMahon, 1975). There are two genera of the family Elephantidae: Elephas and Loxodonta. The Asian elephant (Elephas maximus) is also known as the Indian elephant, and is found in Asia. The elephants of the genus Loxodonta, known collectively as African elephants, are currently found in 37 countries in Africa (Blanc, 2008; Elephant encyclopedia). African elephants have traditionally been classified as a single species. However genetic study has shown that to comprise three distinct subspecies, namely the savanna elephant (Loxodonta africana africana and Loxodonta africana. knochenhaueri), the forest elephant
(Loxodonta africana cyclotis) (Rohland, et al., 2010), all other species and genera of elephantidae like Loxodonta adaurora (the presumed ancestor of the modern African elephants) are extinct (Eggert, et al., 2002).

Elephant anatomy is poorly understood (Hutchinson, et al., 2006) and access to specimens is severely difficult. The pattern of limb called pentadactyl is an example of homologous structure found in all classes of tetrapods. Suggesting that they have originated from a common ancestor but in the course of evolution these fundamental structures have changed. The paw of the dog, the hoof of the horse, the manus and pes of the elephant and foot of the human all share some common features of structure, organization and function. Each of these organisms' foot structures function as the load transmission platform which is essential to balance, standing and locomotion strategies (such as walking, trotting, galloping and running). Elephants as the largest extant terrestrial animals and as the archetype of 'graviportal' animals, having large body size with columnar, robust limbs (Coombs, 1978); provide insight into the biomechanical and physiological constraints that extremely large body size imposes. 
Severe scaling constraint on functional capacity may result as organisms evolve to large size. It has long been recognized that body size is a critical factor influencing mechanical support of animals. Specifically, the ability of muscle to generate force or bones to resist force depends on tissue cross-sectional area which decreases in proportion to an animal's weight with increased size. The scaling of bone and muscle geometry in mammals suggests that force on the skeleton increases with increasing body size. McMahon, (1973) has proposed a scaling model of elastic similarity which argues that the linear dimensions of animals do not increase in the same proportion. Instead bones increase in proportion to their diameter so that animals become distorted in shape and relatively more stout as they increase in size. Yet mammalian limb bones scale close to isometry in proportion (Biewner, 1983). Others (Russell, 1985) do not support this hypothesis instead arguing that large animals must compensate for geometric scaling of their bones by reducing the forces acting on the bones of their skeleton. The most effective way of achieving this reduction is to reduce the bending force. Another mechanism is to reduce ground force exerted on the limb during the support phase of locomotion by reducing the ground contact time (Alexander, et al., 1979). Our understanding of elephant locomotion is impaired by a lack of data.

Hence the objective of this research is to study the anatomy of the long bones of both limbs of the elephant and compare its morphology with some domestic animals, to see if there is an isometric or allometric relationship between the osteometric parameters, describe the skull bone and investigate the biomechanics of the elephant gait.

\section{Materials and Methods}

\section{Osteology}

The elephant (Loxodota africana africana) bones were property of Haramaya University, Ethiopia. Five bones were acquired, two femora, a humerus and two halves of the face bone. The elephant was in the university zoo and died in the year 1960. The condition of the bones was fair with slight erosions of the periosteum, because the bones were stored in outdoors in shed. The femur and humerus of cattle and horse were property of $\mathrm{Ha}$ ramaya University College of Veterinary Medicine, Anatomy Laboratory; they were two years old since slaughtering of the animals. The bones were weighed using a digital balance. The length of bones was measured using a tape measure 
between the two longest distances on the proximal and distal extremities. The circumference of each bone was measured in centimeters mid way on the diaphysis.

Photographs were taken using a Canon IXUS 750 camera. Since the photographs were taken from different distances a ruler of $22 \mathrm{~cm}$ was placed beside the specimen during the photographing in order to scale the size of the structure. All descriptions are according to Nomina Anatomica Veterinaria, 2005.

\section{Biomechanical techniques}

To study the gait of the elephant, video analysis was used as means of identifying the movement patterns through distance and angular measurements. The distance variables describe the stride length and the distances between individual limb placements. For this purpose the following video films were uploaded from the internet all accessed 29 January 2011.

a. Associated Press.Baby elephant runs with herd. http:// www.youtube.com/watch?v=pTHt If2YuRs. February17. 2010. Run time 1:20

b. BBC. Elephant mating, fighting \& pregnancy - BBC Animals. http:// www.youtube.com/watch?v=ODy3 CiS7H40. Added February 17, 2009. Run time 4:02 c. Britannica.com. African-Elephants in their habitat. http:// www. $5 \mathrm{~min} . \mathrm{com} / \mathrm{Video} /$. Run time $2: 43$

d. Indigo film television. The African Elephant. http://www.5min.com/Video/TheAfrican-Elephant-516911223. Run time 4:17

e. Animal Planet Video. Mutual of Omaha's Wild Kingdom: An Elephant Oasishttp:// animal. discovery.com/videos/elephants breaking boundaries an elephant oasis.html. Added: Apr 7, 2009. Runtime: 2:20

f. Animal Planet Video. Mutual of Omaha's Wild Kingdom: Saddest Elephant Ever? http:// animal.discovery.com/videos/elepha nts breaking-boundaries-saddestelephant ever.html. Added: Apr 7, 2009. Runtime: 02:03

g. Animal Planet Video. http://animal.discovery.com/video s/the lost elephants of-timbuktusecrets revealed.html. Added April. 19, 2008. Runtime: 02:56

h. Animal Planet Video. Mutual of Omaha's Wild Kingdom: Elephants form bonds http:// animal.discovery.com/videos/mutual -of-omahas-wild-kingdom-bondsfor-life.html.Added Mar 12, 2008. Runtime 03:00

i. Animal Planet Video. Planet's Best: African Elephant. http:// animal.discovery.com/videos/planet 
s-best-african-elephant.html.

Added May 4, 2009.Runtime 2:22

j. Animal Planet Video, http:// animal.discovery.com/videos/planet $\underline{s}$ best okavango delta elephants.html. Added May 4, 2009. Runtime: 02:32

k. Elephant swimming. http:// www.youtube.com/watch?v=ywX YfLFapLY envymexxx. Added December 4 2006. Run time 2:12 Swimming elephant - Les éléphants nageurs.

http://www.youtube.com/watch? $\mathrm{v}=\mathrm{X}$ Wt_OIXvd8g\&feature=relatedhttp://w ww.youtube.com/user/cousteaucont ent . Added October 31 2008. Run time 2:40

\section{Statistical Analysis}

As there were only few specimens from individual animals of each species no statistical analysis was done. Ratios and percentages were calculated.

\section{Results}

The bones used in this study belong to an elephant which died 50 years ago. Due to lack of data, the age of the animal could not be determined. However, absence of the epiphysal plates (Cartilegio epiphysialis) point out that the animal was adult. And from the combined length of the humerus and femur which was 205 $\mathrm{cm}$, the height at shoulder was estimated to be between $250-320 \mathrm{~cm}$ and the body weight in kilogram was estimated with allometric formula derived from data depicted on Table 1 , to be $2500 \mathrm{~kg}$.

The skull appeared not massive for such animal from the size of tusk buds it was confirmed that the elephant was an adult young female. The morphology of the bones has some similarities and variation. The basic structures are present in all three species with some disparity indicating differences in proportions and muscle and tendon insertion structures.

The cranial and caudal views (Facies cranialis et caudalis) of the femur (Os femoris) are depicted on Plate 1. On the proximal extremity, the head (caput ossis femoris) projects medially and the neck (collum ossis femoris) is longer and less demarcated in the elephant while the trochanter major (trochanter major) and lesser trochanters (trochanter minor) are small and rudimentary in the elephant. Trochanter tertius is well developed in the horse. The shaft (Corpus ossis femoris) is somewhat curved medially in the elephant to help stabilizing the head in the acetablum (Fossa acetabuli). On the distal extremity the medial and lateral condyles (Condylus me- 
dialis et lateralis) ,intercondyle fossa (Fossa intercondylaris) and the trochlea (Trochlea ossis femoris) are less developed indicating less developed articulation for angular rotation.

The arm (brachium) contains a single long bone (Ossa longa). The cranial and caudal surfaces (Facies cranialis et caudalis) are depicted on Plate 2. The head (Caput humeri) is proportional in all of the three species. The neck (Collum anatomicum) is well - developed in the elephant but the lateral or greater tuberosity (Tuberculum majus) and medial or lesser tuberosity (tuberculum minus) are less prominent. The rough prominence (Crista humeri) is highly noticeable. The shaft (Corpus humeri) is spirally twisted and proportionally has a very well developed musclospiral groove (Sulcus $m$. brachialis) in the elephant. On the distal extremity the radial fossa (Fossa radialis), trochlea (Trochlea humeri), the olecranon fossa (Fossa olecrani), the medial and lateral condyles (condylus humeri medialis et lateralis) are less prominent structures in the elephant. However, the lateral epicondyle (epicondylus lateralis) is very well developed.

The skull bone (Cranium) is shown on Plate 3 . The skull is spongy, re- sembling a honeycomb arrangement of the meshwork of trabecular. This gives the face bones (Facies) a lighter weight. The arrows on Plate 3 show that the cranial cavity (Cavum crania) which is small for the size of this animal. The foramen magnum is wide $20 \mathrm{~cm}$ in diameter. However, the atlanto- occipital joint (articulatio atlanto - occipitalis) is less movable in elephant, hence the condyle (condylus occipitalis) of the occipital (Os occipital,) is less developed.

The result of the various osteometric parameters and the ratios are depicted on Table 1. The results show that the femur bone is the longest bone. The proportion of bone length to circumference show that the humerus is more stout than the femur and that the relationship in the three species is isometric, the ratio of the length of femur to the length of humerus. The relationship between bone weight and bone length and circumference in the elephant versus horse and cattle was positively allometric. This shows that the density of bones in elephant is higher than the two other species. Since the live body weight of the horse and cattle was estimated between $250-300 \mathrm{~kg}$, the ratio of weight of the humerus in gram (wh) to its length in centimeter $(/ h)$ or ratio of weight of femur (wf) plus humerus 
$(w h+w f)$ to the length of femur (If) plus of the humerus B BW in $\mathrm{kg}=$ ( $\left.\left.\frac{w h}{l h} x 10\right)\right\}$ or $\left\{\mathrm{BW}\right.$ in $\mathrm{kg}=\left(\frac{w h+w f}{l h+l f} x 10\right)$ \} are good body weight estimators. Hence, using this formula the body weight in $\mathrm{kg}$ were predicted to be $2520 \mathrm{~kg}, 240$ and 230 for elephant, horse (Abyssinian breed) and cattle (Zebu) respectively.

It was observed that the elephant assumes several postures and gaits. The most common gaits of the adult elephant are slow walk, fast walk and trot as shown on Figure 2. The elephants only used controlateral couplets or single footfall pattern. The elephants never had simultaneous whole-body or three legs or two fore or hind legs aerial phase at a time; so they do not run, gallop or jump. The forces acting on the fore and hind leg are shown on figure 1.

The propulsive force comes from opposite hind and forelegs while the two legs remain in contact with the ground as support. The heavy arrows in figure 1 , show the direction of the propulsion. The head is not movable during locomotion. During trotting the elephants .look like as if somebody is pushing them from the back because forelegs are very little flexed and inconspicuous. On standing and swimming the carpal joint (Articulatio carpi) is the most flexible of all the joints and the elbow (articulatio cubiti) can retract $90^{\circ}$.

Relative positions of footprints for different gaits are shown on figure 2. The fore-foot tracks are indicated by black dots and the hind-foot tracks by white dots. Where the hind-foot track registers on the forefoot track it is indicated by a halfblack and half-white dot. Key: (a) slow walk (b) normal walk (c) trot and (d) location of center of gravity. When walking, each of the four feet is lifted and set down on the ground at a different time, each limb moving separately. When trotting, the diagonal feet are placed in pairs at the same time. the right fore-foot and left hind-foot are lifted and set down at the same time, and then the left fore-foot and right hind-foot., two feet are always on the ground When the Elephants walk slowly, the hind-foot track will be behind the fore-foot track, and when it is walking fast the hind-foot track will be in front of the fore-foot track.

Figure 2, (d) shows a schematic drawing of the location of the center of gravity. A, B, C, D represents the points of contact between the feet and ground seen from above. The center of gravity in the elephant is located between the triangle points A, B, E. The elephant is able to lift either its right or its left hind foot and 
the trunk is supported by the feet $A, B, C$ or $A, B, D$. When the center of gravity is shifted to $C, D, E$ the elephant can lift either the left or the right fore foot. In trotting the center of gravity remains point " $\mathrm{O}$ " so that the elephant is able to support the body on two opposite legs $A$ and $D$ or $\mathrm{B}$ and $\mathrm{C}$.

\section{Discussion}

The limbs of elephants reveal many peculiarities both in structure and in kinematic patterns. In this study the linear measurements of the bones have shown an isometric scale in the three species studied; elephants, horses and cattle. Allometric scaling between bone circumference and length gave a good estimate of the body weights which is about 10 times the ratio (Weight in grams divided by length). Similar results were observed in mammals by Christiansen (2002) and Alexander (2009). The weight of bones could vary from time to time and according to the condition of preservation, accordingly there is limitation of the allometric equation. In the present study, the weight of the femur was 21.5 while the humerus was 24 $\mathrm{kg}$. In most mammalian species the femur is considered the longest and the heaviest bone. In this study we could not confirm if the lower weight of the femur is inherent to elephants or due to preservation condition of the bone. It might have been destructed by saprophytic bacteria. The larger circumference of the forelimb sole might be related to the assumption that also in graviportal elephants the majority of the body weight rests on the forelimbs, as occurs in cursorial, quadrupedal mammals (Alexander, 1979), for this reason, the humerus could be heavier than the femur.

As an alternative, isometric scales could be used to predict a body weight (Anderson, and Hall-Martin, 1985; Bonnan, 2007). Despite the fact that the center of gravity in elephants is forward biased, the head is lighter. This is due to the skull bones architecture which is meshwork of trabeculae giving them a spongy structure. (Vandermerwe et al., 1995).Male African elephants possess a distinctive head shape compared with females: the head of the male is more massive than that of a female. This is one reason why we classified our skull specimen to be for a female elephant.

It is generally recognized that if bones of animals are geometrically similar, their length increases in direct proportion to their diameter. Stress acting on them should increase with increasing size (Ren, et al., 2008). This is because the strength of a bone, or its ability to 
withstand stress compression is proportional to its crossectional area where as the forces acting on bone are proportional to some multiple of the body weight (Alexander et al., 2009; Biewner,1989). Contrary to the study by McMahon, (1989), in this study a decrease in proportion of the bone length to circumference or stoutness in elephants was not observed.

An increase in bone density was detected and could be interpreted as a mechanism of adaptation of the elephant's appendicle skeleton to its heavy weight.

In terrestrial vertebrates, the masses of most appendicular bones scale with significant positive allometry. These include the pectoral and pelvic girdles, humerus, radius \& ulna, and metacarpus. Total hind limb mass and the masses of individual hind limb bones (femur, tibia, and metatarsus) scale isometrically (Anderson and Hall-Martin, 1985). Metapodial mass correlates more poorly with body mass than the girdles or any of the long bones. The mid-shaft circumferences of the humerus and femur are closely related to body weight in living terrestrial vertebrates. Because these elements are frequently preserved in subfossil and fossil vertebrate skeletal materials, the relationship can be used to estimate body weight in ex- tinct vertebrates (Anderson and Hall-Martin, 1985).

Limb bones of Loxodonta are somewhat slender: their isometric rather than allometric scaling would predict their size. The articular surfaces of the distal extremities and proximal extremity of the elephant femur and humerus were less developed this is in agreement with the results of (Christiansen, 2002) that bone joints do not flex greatly in the elephant. Distal ends of bones were nearly as massive as proximal ends which would not conserve energy in the non-propulsive phase of movement (Weissengruber, et al., 2006). The skeleton is comparatively inflexible and characterised by vertically oriented legs and a ridged nearly horizontal spine offering support for a heavy body (Vandermerwe, et al., 1995). The upper and lower parts of the limb align vertically with each other when the limb is extended and thus a mass of the animal is carried on the legs that are like columns or pillars. Elephants do not run and there is no free flight phases in which all feet are off the ground at the same time. The maximum rearward and foreword extension of moving legs are shorter during a walk then fast walk and greater in trot (Hutchinson, et al., 2006). All angular velocities decrease with increasing size (Alexande, et al., 1977). 
At the instant, the hoof strikes the ground, it is rapidly decelerated, and this sends a shock wave up in the horse's limb. The shock wave is characterized by having a high amplitude and rapid vibration frequency; these characteristics make it particularly damaging to the bones and joints (Barrey, 1987; Leleu, et al., 2005). In the elephant the foot pad is rubbery and it is filled with adipose tissue similar to the camel foot pads which act like a car tyre filled with fat instead of air Bligh et.al. 1976 (Cited by Mukassa, 1981). The uniquely designed limbs of the African elephant, Loxodonta africana, support the weight of the largest terrestrial animal; besides other morphological peculiarities, the feet are equipped with large subcutaneous cushions which play an important role in distributing forces during weight bearing and in storing or absorbing mechanical forces when loaded. The cushion is compressed and expands medially and laterally. In unloaded hind feet of elephants the sole surface is convex (Weissengruber, et al., 2006) .The effects of impact shock are responsible for the development of problems such as arthritis. Activities that involve running or jumping, in which there is an airborne phase, are much more damaging than walking or stepping, in which there is always at least one foot on the ground. As the largest extant terrestrial animals, elephants do not trot or gallop but can move smoothly to faster speeds without markedly changing their kinematics, yet with a shift from vaulting to bouncing kinetics (Biewner, 1989). Differences in limb posture and locomotor performance have profound influence on the amount of stress set up in the appendicular bones during rigorous physical activity (Christiansen, 1999). This makes them less predisposed to arthritis and fracture. The capacity of weight bearing of the elephant is not comparable with obese humans, the elephants bones are scaled proportionally but not in the latter.

The carrying forces recorded by the force platform indicate how the weight is distributed between the front and hind limbs. In a standing horse the front limbs carry about $55 \%$ of the horse's weight, the hind limbs about $45 \%$. However in the elephant weights are on the fore limb (Leleu, et al., 2005). The hind limbs become almost entirely responsible for providing propulsion. The front limbs lose most of their propulsive thrust instead they provide more braking, which is used in combination with the carrying force of the front limbs to push the shoulders and forehand upwards and backwards (Sissons, et al., 1975). Therefore, raising the forehand is 
much more than simply a result of lowering the hindquarters, it is an active process brought about by the action of the front limbs. Cattle are kept in confinement, most studies focus on lameness thus locomotion and kinematic studies of domestic animals have been almost solely focused on horses (Fredricson, et al. 1989). The natural gaits of cattle are walking, trotting or galloping (Raven, 1989). Normally they move relatively slow walking pace, they trot when they have to move fast and this movement might change into gallop only for short distance. The head is mobile and the limbs are angular. In all the tree species the propulsion force comes from the hind limb.

However, in elephants the head moves very little dorsoventrally or laterally. The elephant should turn its body to see things behind. The shape of the head is conical and it serves as cone nose making the elephant aerodynamically efficient, including during swimming, when the elephants moves the trunk stays straight down used as front splitter.

In conclusion understanding the role of the feet of a variety of different organisms in a wide range of body types, foot shapes, arrangement of structures, loading conditions and other variables is important to the understanding of biomechanics and predisposing factors to lameness, arthritis and fractures. Comparing bone morphology and allometry can be a tool in archeological and forensic research, and help to solve problems of Shoe and prosthetic engineering.

\section{References}

Alexander, R. M. Jayes, A. S.

Maloiy, G. M. $O$ and Wathuta, E. M. (2009): Allometry of the limb bones of mammals from shrews (Sorex) to elephant (Loxodonta). Journal of Zoology.189 (3) 305-314. DOI: $10.1111 /$ j.14697998.1979.tb03964.x.

Alexander, R. Maloiy, G.M.O.

Hunter, B. Jayes, A.S. and Nturibi, J. (1979): Mechanical stresses in fast locomotion of buffalo (Syncerus caffer) and elephant (Loxodonta africana). J. Zool. 189: 135-144.

Alexander, R.M. Langman, V.A. and Jayes, A.S. (1977): Fast locomotion of some African ungulates. J. Zool. 183, 291300.

Anderson, J.F and Hall-Martin, A.

(1985): Long-bone circumference and weight in mammals, birds and dinosaurs. Journal of Zoology. 207 (1): 
53-61. DOI: 10.1111/j.14697998.1985.tb04915.x.

Barrey, E. (1987): Foot Biomechanics in the Normal Horse: A study of the Hoof Force Distribution in the Forelimb with a New Measuring Method. http://w4.ub.uni konstanz. de/cpa/article/viewFile/2355/ 2225

Biewner, A.A. (1983): Allometry of quadripedal locomotion: The scaling of duty factor, bone curvature and limb orientation to body size. J. exp. Biol.105:47-171.

Biewner, A.A.(1989): Scaling sup port in mammalian limb. Science News Series. 245: (4913) 45-48.

Blanc, J. (2008): Loxodonta Africa na. In: IUCN 2010. IUCN Red List of Threatened Species. Version 2010.4. $<w w w$.iucnredlist.org $>$. Downloaded on 31 January 2011.

Bonnan, M.F. (2007): Linear and ge ometric morphometric analysis of long bone scaling patterns in Jurassic neosauropod dinosaurs: their functional and paleobiological implications. Anat Rec (Hoboken). 290(9):1089-111

Christiansen, P. (1999): Scaling of the limb long bones to body mass in terrestrial mammals
Journal of Morphology. 239 $:(20)$ 167-190.

DOI: $10.1002 /$ (SICl)10974687(199902)239:2<167::Al D-JMOR5>3.0.CO;2-8

Christiansen, P. (2002): Mass alometry of the appendicular skeleton in terrestrial mammals. Journal of Morphology. 251: (2) 195-209. DOI: 10. 1002 / J. mor.1083.

Coombs, W.P. (1978): Theoretical aspects of cursorial adaptations in dinosaurs. Quarterly Rev. Biol. 53(4): 393-418.

Eggert, L.S. Rasner, C.A. and Woodruff, D.S. (2002): The evolution and phylogeography of the African elephant inferred from mitochondrial DNA sequence and nuclear microsatellite markers. Proc. R. Soc. Lond. B 269, 19932006. DOI 10.1098/ rspb. 2002. 2070.

Fredricson, I. Drevemo, S. Dalin, G. Hjertén, G. Björne, K. and Rynde, R. (1983): Treadmill for equine locomotion analysis. Equine Vet. J. 15(2), 111- 115.

Elephant encyclopedia.

http://www.upali.ch/elephant _encyclopedia.html

www.elephantmagazine.org.

Hildebrand, M. (1984): Rotations of the leg segments of three fast-running cursors and an 
elephant. J. Mammal. 65: 718-720.

Hutchinson, J.R, D. Schwerda, D. J. Famini, R. H. I. Dale, M. S. Fischer and R. Kram, (2006): The locomotor kinematics of Asian and African elephants: changes with speed and size. The Journal of Experimental Biology. 209: 3812-3827

Hutchinson, J.R. Schwerda, D.

Famini, D. Dale, R.H.I. Fischer, $M$ and Kram, $R$. (2006): The locomotor kinematics of African and Asian elephants: changes with speed and size. Journal of Experimental Biology. 209: 3812-3827.

Leleu C. Cotrel C.and Barrey,

E. (2005): Relationships between biomechanical variables and race performance in French Standard bred trotters. Livestock Production Science. 92 I (1) Pages 3946.

McMahon, T.A. (1973): Size and shape in biology. Elastic criteria impose limits on biological proportions, and consequently on metabolic rates. Science. 179(4079): 12011204.

McMahon, T.A. (1975): Using body size to understand the structural design of animals:
Quadrupedal locomotion. J. App. Physiol. 39(4): 619627.

Mukasa-Mugerewa, E. (1981): The camel (Camelus dromedaries): a bibliographical review. ILCA. Monograph. Addis Ababa, Ethiopia. pp71

Nomina Anatomica Veterinaria. (2005): $5^{\text {th }}$ ed. International Committee on Veterinary Gross Anatomical Nomenclature (I.C.V.G.A.N.). Knoxville, TN. USA. Toussaint E. Raven T.E. 1989. Cattle Foot Care and Claw Trimming. Farming Press, Ipswich, UK

Ren, L. Butler, M. Miller, C. Paxton, H. Schwerda , D. Fischer, M.S and Hutchinson, J.R. (2008): The movements of limb segments and joints during locomotion in African and Asian elephants. J Exp Biol. 211(17):2735-51.

Rohland, N. Reich, D. Mallick, S. Meyer, M. Green R.E. (2010): Genomic DNA Sequences from Mastodon and Woolly Mammoth Reveal Deep Speciation of Forest and Savanna Elephants. PLoS Biol 8(12): e1000564. doi: 10.

1371/journal.pbio.1000564 Russell, D.A. (1985): Scaling of the 
limb long bones to body mass in terrestrial mammals Journal of Zoology. 207: (1) 53-61.

Sissons, S. Grossman, J and Getty, R. (1975): The anatomy of domestic animals. $5^{\text {th }}$ eds. Saunders Company USA Vandermerwe, N.J. Bezuidenhout, A.J and Seegers, C.D. (1995): The skull and mandible of African elephant
(Loxodonta africana). Journal of Veterinary Research. 62:245-260

Weissengruber, G. E. Egger, G. F. Hutchinson, J. R. Groenewald, H. B. Elsässer, L. Famini, D and Forstenpointner, G. (2006): The structure of the cushions in the feet of African Elephants (Loxodonta Africana). Journal of Anatomy.209: (6)781-792

Table (1): Osteometric parameters of African elephant, horse and cattle

\begin{tabular}{llll}
\hline Parameter & Elephant & Horse & Cattle \\
\hline Length of femur (cm) & 110 & 40 & 36 \\
Circumference of femur (cm) & 44 & 14.5 & 13 \\
Femur length circumference ratio & 2.5 & 2.75 & 2.8 \\
Length of humerus (cm) & 95 & 32 & 33 \\
Circumference of humerus (cm) & 40 & 14 & 14 \\
Humerus length to circumference ratio & 2.3 & 2.3 & 2.35 \\
Ratio of femur to humerus & 1.15 & 1.25 & 1.29 \\
Weight of humerus (g) & 24000 & 783 & 747 \\
Weight of femur (g) & 21500 & 959 & 1097 \\
Ratio of weight of femur to humerus & 1.11 & 0.82 & 0.68 \\
Combined length of femur and humerus & 205 & 72 & 64 \\
Femur weight to length ratio & 195 & 24 & 30 \\
Femur weight to circumference ratio & 537 & 66 & 84 \\
Humerus weight to length ratio & 252 & 24 & 23 \\
Humerus weight to circumference ratio & 600 & 56 & 53 \\
Ratio of weight of femur plus humerus to length of femur plus hu- & 222 & 24 & 28 \\
merus ratio & & & \\
Ratio of weight of femur plus humerus to circumference of femur \\
plus humerus
\end{tabular}



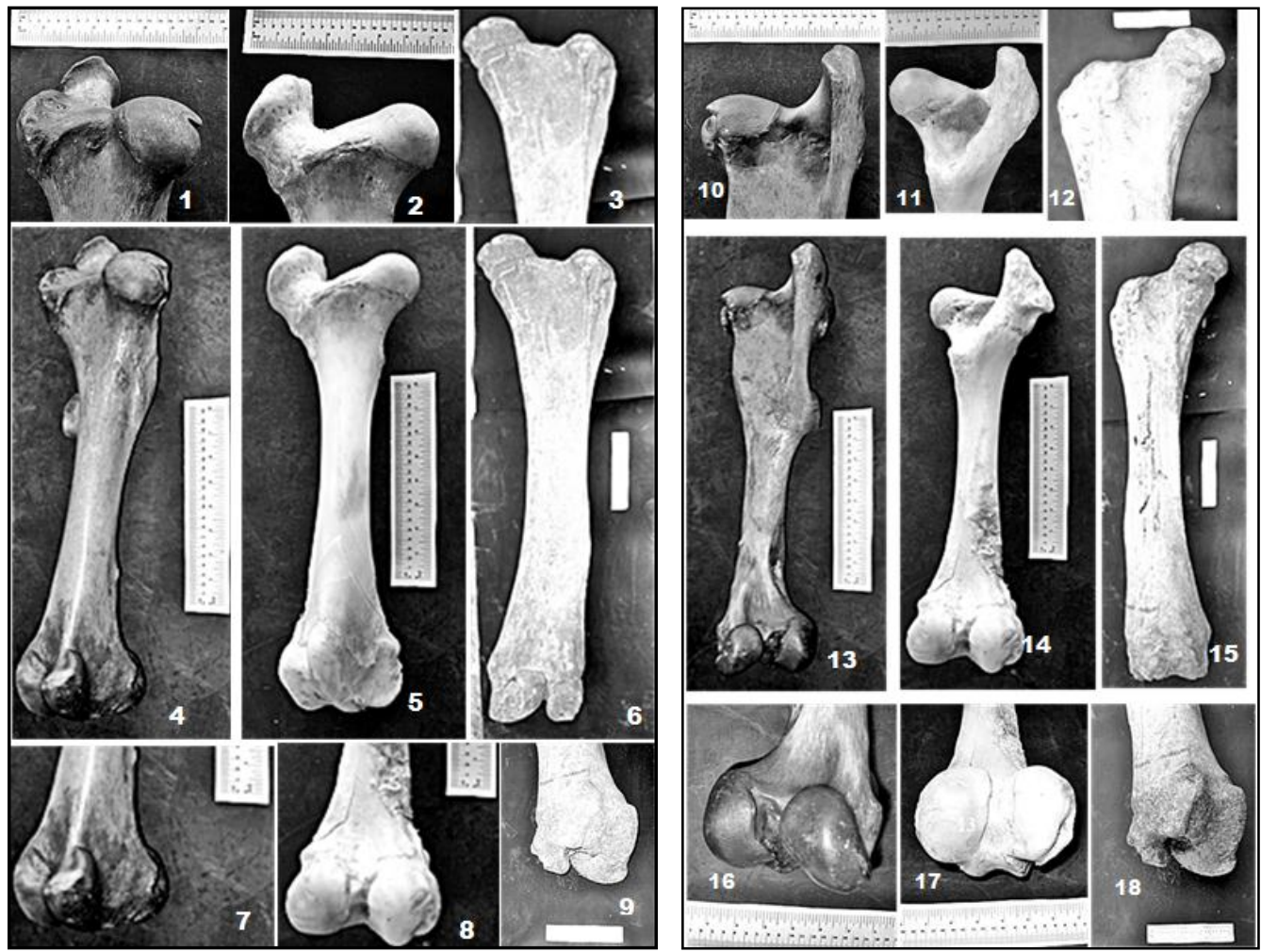

Plate (1): Photos from right to left are femora of horse, cattle and elephant respectively. Photos 4- 6 are frontal views of the femora, 1-3, frontal views of proximal extremities, 7 9 frontal views of distal extremities. 13- 15 are caudal views of the femora,10-12 are caudal views of proximal extremities and 16-18 caudal views of and distal extremities. 

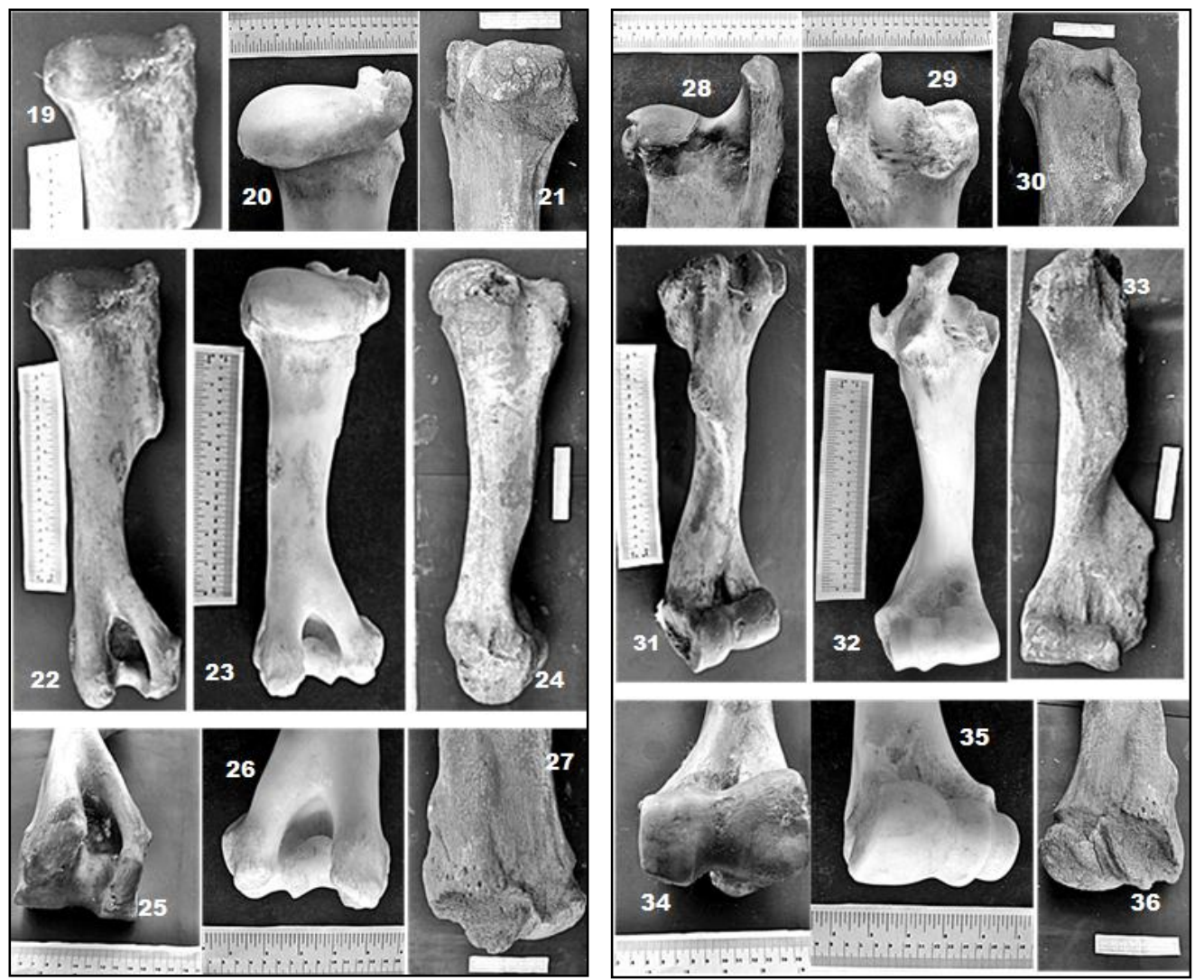

Plate (2): Photos 22-24 from right to left are humera of horse, cattle and elephant respectively. Photos 19-21, frontal views of proximal extremities, 25-27 frontal views of distal extremities. 31-33 are caudal views of the humera; 34-36 are caudal views of proximal extremities

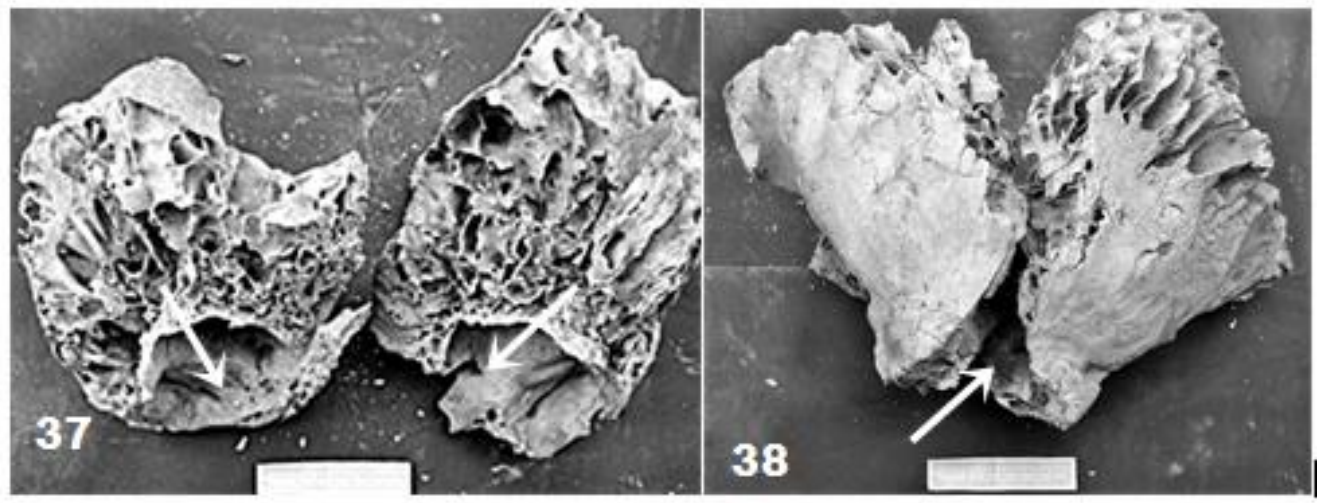

Plate (3): Photos 37 is a longitudinal section of the cranium of elephant arrows show the cranial cavity and photo 38 is a dorsal view. Arrow indicates the foramen magnum. 


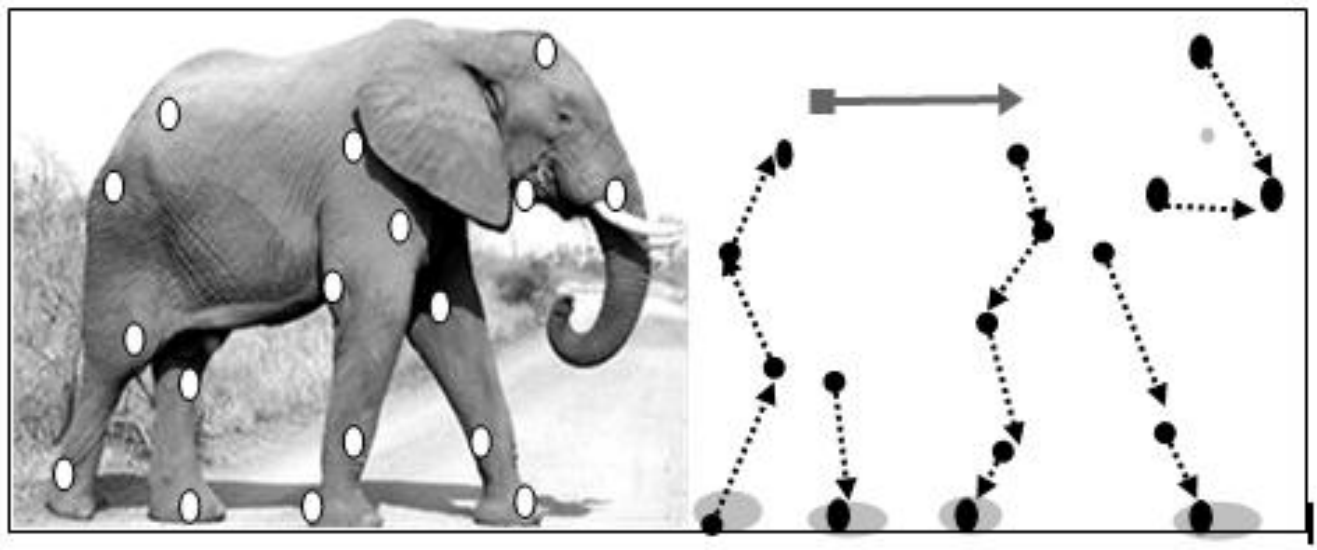

Fig (1): Biomechanics and direction of forces in the elephant foot during locomotion

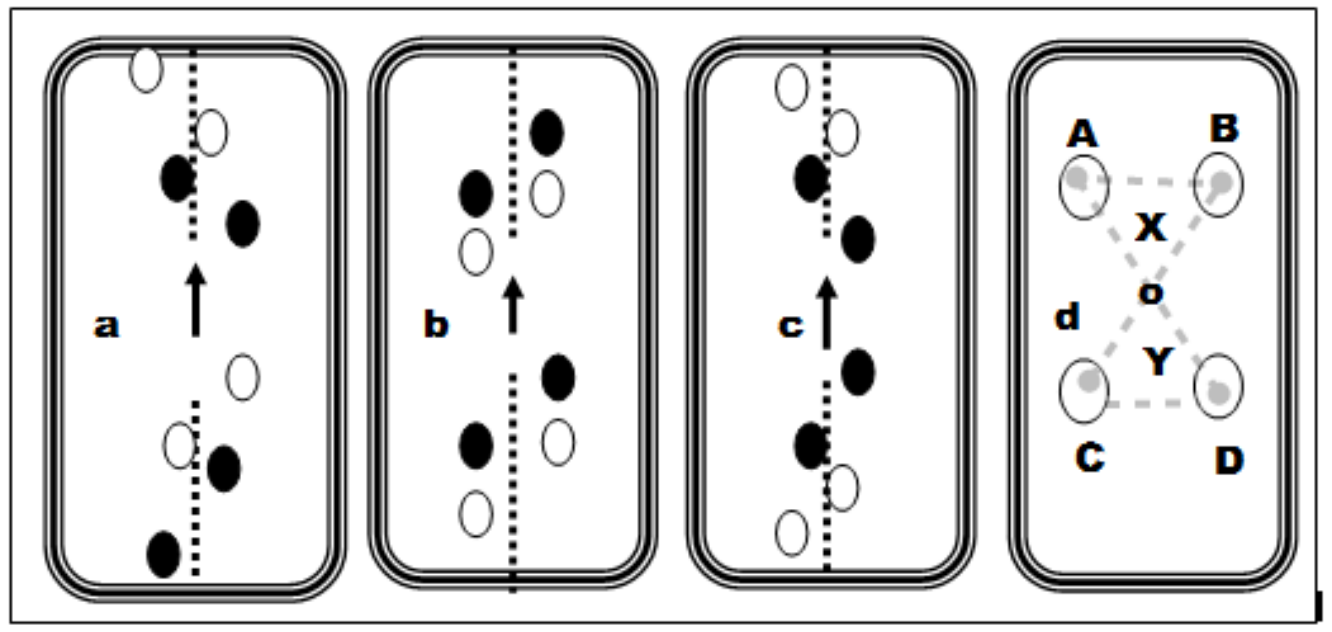

Fig (2): Kinematic analysis of the elephant foot

The fore-foot tracks are indicated by black dots and the hind-foot tracks by white dots. Where the hind-foot track registers on the fore-foot track it is indicated by a half-black and half-white dot. Key: (a) slow walk (b) normal walk (c) trot and (d) location of center of gravity. 


\section{Animals of this issue}

\section{African bush elephant (Loxodonta Africana)}

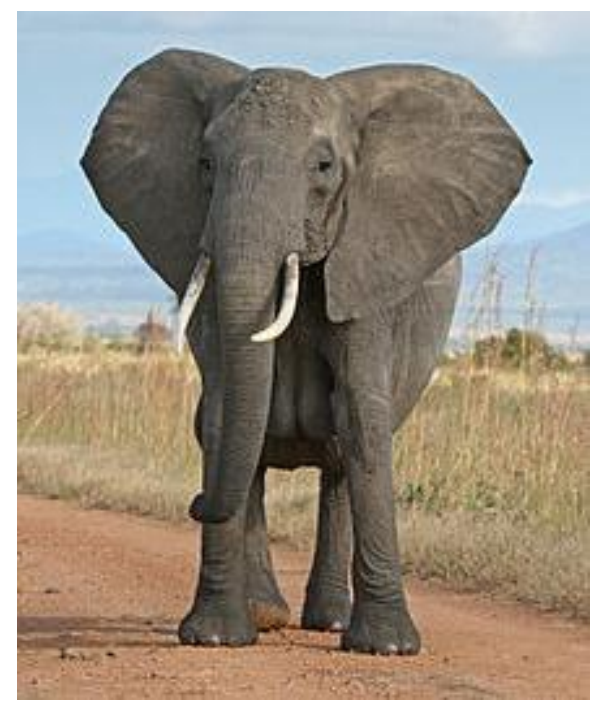

Kingdom: Animalia, Phylum: Chordata, Subphylum: Vertebrata, Class: Mammalia, Superorder: Afrotheria, Order: Proboscidea, Family: Elephantidae, Genus: Loxodonta \& Elephas

Elephants are large mammals of the family Elephantidae and the order Proboscidea. They are represented by three extant species: the African bush elephant (Loxodonta africana), the African forest elephant (L. cyclotis) and the Asian elephant (Elephas maximus). The two African species were traditionally considered to be two different subspecies, in the same species. These three species are scattered throughout sub-Saharan Africa and South to Southeast Asia. They are the only surviving proboscideans, although several extinct species have been identified, including the elephants' close relatives, the mammoths. Elephants are the largest living terrestrial animals. Male African bush elephants can reach a height of 3.20-4 m (10.5-13.1 ft) and a weight of $4,700-6,048 \mathrm{~kg}(10,362-13,334 \mathrm{lb})$. The animals have several distinctive features, including a long proboscis or trunk that they use for numerous purposes, particularly for grasping objects. The ear flaps are particularly large and help to control the temperature of their massive bodies. Their incisors grow into large tusks, which serve as tools for digging and moving, as well as weapons for fighting. The African species have larger ears and concave backs while the Asian elephant has smaller ears and a convex back.

(Source: Wikipedia) 